\title{
HEPTAGONAL TRIANGLE AS THE EXTREME TRIANGLE OF DIXMIER-KAHANE-NICOLAS INEQUALITY
}

\section{Vladimir Volenec, ZdenKa KOLAR-BEgOVIĆ AND RUŽICA KOLAR-ŠUPER}

Abstract. Let $T$ be a triangle in the Euclidean plane. Let $g(T)$ be the orthic triangle of the triangle $T$, and let $g^{n+1}(T)$ be the orthic triangle of the triangle $g^{n}(T)$. In [2] it is proved that for $n \rightarrow \infty$ the triangle $g^{n}(T)$ tends to the point $L$. It has also been shown that $|O L| \leqslant \frac{4}{3} R$ for all triangles $T$ and that $|O L|=\frac{4}{3} R$ if $T$ is a heptagonal triangle, where $(O, R)$ is the circumscribed circle of the triangle $T$.

In this paper it will be geometrically proved that the equality in Dixmier-Kahane-Nicolas inequality $|O L| \leqslant \frac{4}{3} R$ is valid in the case of a heptagonal triangle. The relationship between the initial heptagonal triangle $T$ and the obtained point $L$ will also be investigated.

Mathematics subject classification (2000): 51M04.

Keywords and phrases: heptagonal triangle, indirect similarity.

\section{REFERENCES}

[1] L. Bankoff, J. Garfunkel, The heptagonal triangle, Math. Mag., 46 (1973), 7-19.

[2] J. Dixmier, J.-P. Kahane, J.-L. Nicolas, Un exemple de non-dérivabilité en géométrie du triangle, Ens. Math., 53, 2 (2007), 369-428.

[3] R. Kolar-ŠUPeR, Z. KOlaR-Begović, V. VOlEnec, Two characterizations of the triangle with the angles $\frac{\pi}{7}, \frac{2 \pi}{7}, \frac{4 \pi}{7}$, International Journal of Pure and Applied Mathematics, 44 (2008), 335-338.

[4] V. ThéBault, Bibliographie des triangles et des tétraèdres spéciaux, Bull. Soc. Roy. Sci. Liège, 19 (1950), 574-607. 